\title{
Português Língua Estrangeira: uma proposta de ensino sistêmico
}

\author{
Tânia Maria Moreira* \\ Guilherme Barbat de Barros**
}

\begin{abstract}
Resumo
Desde o anúncio da necessidade de ações que versem sobre a internacionalização no âmbito do Ensino Superior brasileiro, inúmeros foram os projetos e programas propostos e desenvolvidos em universidades federais, dentre os quais se destaca o Idiomas sem Fronteiras (IsF). Nesse sentido, tendo como finalidade dar visibilidade e compartilhar estudos e práticas de ensino, este artigo tem como objetivo apresentar princípios do Ciclo de Ensino e Aprendizagem norteadores no desenvolvimento de cursos de Português como Língua Estrangeira no IsF na Universidade Federal de Santa Maria (UFSM), bem como os resultados de uma experiência docente, vivenciada a partir de um levantamento qualiquantitativo e interpretativista envolvendo discentes estrangeiros matriculados em cursos de graduação e pós-graduação na UFSM. Desse modo, a perspectiva teórica e metodológica adotada se baseia nos estudos de Martin e Rose (2008) e Rose e Martin (2012). Os resultados alcançados sinalizam o perfil de acadêmicos estrangeiros na universidade e apontam algumas de suas demandas de aprendizagem sobre a Língua Portuguesa usada no Brasil. A experiência realizada envolveu o desenvolvimento de atividades de desconstrução, construção
\end{abstract}

\footnotetext{
* Universidade Federal do Sul e Sudeste do Pará (Unifesspa). Doutora em Letras. Professora em exercício provisório no Departamento de Metodologia de Ensino da Universidade Federal de Santa Maria (UFSM), Coordenadora do idioma Português Língua Estrangeira ou Adicional do Núcleo de Línguas-ISF, no âmbito da Rede Andifes Idiomas sem Fronteiras (IsF) - PLE/ PLA da UFSM. ORCID: https://orcid.org/0000-0001-8657-7385.

** Universidade Federal de Santa Maria. Licenciando em Letras - Português e literaturas de língua portuguesa. Professor bolsista de Português Língua Estrangeira no IsF-UFSM. ORCID: https://orcid.org/0000-0003-1544-4707.
} 
conjunta e individual de textos e resultou na publicação de um livreto de resenhas de filmes. Os textos produzidos pelos alunos serviram como instrumento de avaliação do processo de ensino e aprendizagem e da eficácia dos postulados de Martin e Rose (2008) e Rose e Martin (2012) no contexto situado.

Palavras-chave: Português Língua Estrangeira. Rede Idioma sem Fronteiras. Ciclo de Ensino e Aprendizagem.

\section{Portuguese Foreign Language: a systemic education proposal}

\section{Abstract}

Since the announcement of the need for actions that deal with internationalization in the Brazilian Higher Education context, innumerable projects and programs have been proposed and developed in federal universities, among which the Idiomas sem Fronteiras (IsF) outstands. In this way, for purposes of giving visibility and sharing studies and teaching practices, this paper aims to present principles of the Teaching and Learning Cycle that guide the development of Portuguese as a Foreign Language courses at IsF at the Federal University of Santa Maria (UFSM), as well as the results of a teaching experience, lived from a qualitative-quantitative and interpretative survey involving foreign students enrolled in undergraduate and graduate courses at UFSM. Thus, the theoretical and methodological perspective adopted is based on Martin and Rose (2008) and Rose and Martin (2012) studies. The achieved results signal the foreign academics profile at the university and point out some of their learning demands regarding the Portuguese language used in Brazil. The experience involved the development of deconstruction activities, joint and independent texts construction and resulted in a film reviews booklet. The texts produced by the students 
served as an instrument for the teaching and learning process evaluating and the effectiveness of the Martin and Rose (2008) and Rose and Martin (2012) postulates in this situated context. Keywords: Post-90 Portuguese poetry of the 20th century. Poetry magazines. Critiscism of poetry. Contemporary culture.

Recebido em: 19/03/2021 // Aceito em: 14/04/2021. 


\section{Introdução}

Vivemos, cada vez mais, em um mundo interconectado, interpelados pelo aumento contínuo do fluxo de culturas, conhecimentos e tecnologias. Isso é reflexo da sociedade contemporânea, a qual é, inevitavelmente, afetada pela globalização. Em suma, é um dos efeitos concretos dessa nova forma de viver a intensificação de deslocamentos de sujeitos em diferentes processos de migração.

Nessa nova ordem mundial, tais processos, de acordo com Welp, Fontes e Sarmento (2016), impactam significativamente a área da educação, pois ela pode se configurar tanto como sendo um agente da globalização, quanto um de seus reagentes. Ratificando o exposto, Knight (2008) aponta implicações da globalização na internacionalização do Ensino Superior. Na mesma direção reflexiva, no Brasil, especialmente a partir de 2012, com a publicação de um documento intitulado Programa de expansão, excelência e internacionalização das universidades federais (ANDIFES, 2012), esses novos desafios do contexto educacional vêm sendo amplamente discutidos e implementados no Ensino Superior.

Dentre as ações realizadas nesse nível de ensino, destacamos o documento assinado pela Andifes ${ }^{1}$ indicando algumas medidas necessárias, tendo em vista a qualificação do Ensino Superior em tempos de internacionalização. São elas:

- adequar academicamente a universidade, em seu aspecto qualitativo e quantitativo, às novas demandas, dinâmicas, escalas e aos novos papéis e contextos globais advindos da sociedade do conhecimento, cada vez mais fortalecido neste início de século;

1 Andifes - Associação Nacional de Dirigentes de Instituições Federais de Ensino Superior. 
- formar, estrategicamente, mão de obra qualificada para as necessidades sociais, econômicas e com padrões apropriados de sustentabilidade para este novo ciclo de crescimento e desenvolvimento que se expressa atualmente no país e no mundo;

- produzir ciência, tecnologia e inovação para inserir o país, com soberania, na nova ordem mundial do conhecimento;

- produzir e transmitir um conhecimento que promova a igualdade, a inclusão e auxilie na formação de cidadãos emancipados e portadores de conceitos éticos e humanitários. (ANDIFES, 2012, p. 6).

Desde o anúncio da necessidade dessas ações, inúmeros foram os projetos e programas propostos e desenvolvidos em universidades de âmbito federal, dentre os quais se destaca o Ciências Sem Fronteiras (CSF), cuja principal estratégia estava relacionada ao intercâmbio de estudantes. Para preparar linguisticamente alunos do Ensino Superior para a realização de intercâmbio, surge, na mesma época do CSF, o Inglês sem Fronteiras, o qual, no ano de 2014, passa a se chamar Idiomas sem Fronteiras (IsF) e a promover o ensino de outras línguas além do inglês, dentre elas o Português para Estrangeiros.

A inclusão do ensino de Português Língua Estrangeira (PLE) no âmbito do IsF tem um objetivo duplo: por um lado, visa a desenvolver a proficiência linguística de estrangeiros em português do Brasil e, por outro, contribuir com a formação profissional teórica na área de PLE, cuja demanda vem se intensificando nos últimos anos. O aumento dessa demanda está relacionado diretamente à internacionalização e à abertura de vagas específicas para estudantes estrangeiros em instituições de Ensino Superior brasileiras, vagas oriundas, muitas vezes, de acordos bilaterais com instituições educacionais de outros países. 
Visando a contemplar o item dois no documento assinado pela Andifes e os objetivos do PLE-IsF, neste artigo, reportamos as bases teóricas e metodológicas da pedagogia da Escola de Sidney e informações relativas às experiências de investigação e ensino realizadas nessa área. Assim, este trabalho tem por objetivo apresentar princípios do Ciclo de Ensino e Aprendizagem (CEA) norteadores no desenvolvimento de cursos de Português como Língua Estrangeira do Idioma sem Fronteiras da Universidade Federal de Santa Maria (UFSM), bem como os resultados de uma experiência docente, vivenciada a partir de um levantamento qualiquantitativo e interpretativista envolvendo discentes estrangeiros matriculados em cursos de graduação e pós-graduação na UFSM, com a finalidade de dar visibilidade e compartilhar estudos e práticas de ensino. Para isso, além desta introdução, na sequência, encontram-se as seções de referencial teórico, metodologia, análises e considerações finais.

\section{Referencial teórico}

Nesta seção, agrupamos as reflexões teóricas em dois momentos. Inicialmente, apresentamos a definição de PLE, as ações e as projeções no âmbito dessa área. $\mathrm{Na}$ sequência, reportamos os princípios da Pedagogia de Gênero mobilizados neste trabalho.

\subsection{Ensino de Português Língua Estrangeira}

PLE é uma especialidade da área de ensino e aprendizagem de línguas em emergência no Brasil (ALMEIDA FILHO, 2005; 
2007; DINIZ, 2008; 2012; LEFFA, 1999; MOITA LOPES, 2013; OLIVEIRA, 2013; ZOPPI FONTANA, 2009; ROCHA, 2019). Conforme Almeida Filho (2011, p. 724), desde o final dos anos 70, essa área vem emergindo cientificamente, muito embora o ensino de PLE tenha uma "longa história, enquanto campo de trabalho e ofício realizado na forma de treinamento de praticantes desejosos de ingressar no ramo". É sabido que, desde 1550, o ensino de PLE é ministrado por "professores improvisados" (ALMEIDA FILHO, 2011, p. 97), ou seja, sem formação acadêmica adequada para ensinar os aprendizes a falar, ler e escrever em português.

A consolidação desse campo de ensino está relacionada a movimentos políticos, econômicos, sociais, globais e culturais. Conforme Rocha,

[...] a criação do Mercosul, em 1989; as parcerias econômicas do Brasil com outros países (como China) e seu reconhecimento como um dos países emergentes economicamente (BRICs); os deslocamentos de sujeitos pelo mundo em um processo de desterritorialização (MOITA LOPES, 2013); as novas tecnologias de comunicação que interligam os sujeitos no mundo como um grande globo interconectado; o processo de globalização e ruptura de fronteiras; entre outros, como também, a meu ver, por um novo modo de se interessar/aprender línguas instaurado pelo ensino inter, trans e multicultural, que tem promovido o respeito e a negociação das diferenças entre as línguas e culturas; movimentos que promovem outro olhar e novos sujeitos professores no campo de Língua Estrangeira (doravante LE) e em especial de PLE. (ROCHA, 2019, p. 103).

Esses movimentos fizeram com que, no contexto brasileiro e mundo afora, pesquisadores e professores da área de Letras e Linguística Aplicada passassem a realizar ações, tais como desenvolver estudos e reflexões críticas sobre o ensino e a 
aprendizagem de PLE; publicar artigos científicos relacionados ao ensino e à aprendizagem de estrangeiros; criar uma associação com o objetivo de congregar professores e pesquisadores, do Brasil e do exterior, da área com vistas ao desenvolvimento de atividades e iniciativas de cunho acadêmico e sociopolítico; ofertar cursos de formação de professores; elaborar estratégias e materiais didáticos embasados teoricamente, conforme tendências de ensino e aprendizagem vigentes no ensino desse idioma, que vêm se consolidando.

No que tange às tendências de ensino e aprendizagem em PLE, Almeida Filho (2011) destaca as marcantes práticas de ensino orientadas pelo uso de uma visão tradicional, associada a alterações superficiais em termos de métodos, técnicas ou recursos adotados em alguns contextos no Brasil. Para o referido pesquisador, a tendência educacional na área de PLE, adequada ao momento histórico e social, é a abordagem comunicacional, pois ela reúne um conjunto de conceitos e ideias que contribuem para a evolução do aluno em termos de aprendizagem linguística e comunicação, formando um usuário competente da língua-alvo em diferentes contextos de interação propositadas.

Já Furtoso (2001), com base em estudos prévios (RICHARDS; NUNAN, 1990; ASSIS-PETERSON, 1999; PRABHU, 1990; ALLWRIGHT, 1991; KUMARAVADIVELU, 1994), destaca reflexões sobre o pós-método como uma alternativa que proporciona autonomia ao professor, como investigador da sua própria prática de ensino, na escolha acerca da abordagem, dos princípios e das decisões de o que fazer em práticas de ensino e aprendizagem de uma língua estrangeira. Documentos oficiais que abordam questões de ensino de linguagem e de Língua Portuguesa, por sua vez, tais como a Lei de Diretrizes e Bases 
da Educação Nacional (1996) e os Parâmetros Curriculares

Nacionais de Língua Portuguesa (1998), também apontam para a adesão da diversidade metodológica, a pluralidade de princípios e concepções pedagógicas e o ensino de linguagem mediado por gêneros. Diante do exposto, cabe perguntar como enfrentar a tarefa de ensinar PLE com excelência e atender às demandas da docência, usando, de fato, princípios que se ajustem a uma abordagem com foco no uso da linguagem.

Estudos mostram que a Pedagogia de Gênero, oriunda de um projeto articulado por pesquisadores da Escola de Sidney, ${ }^{2}$ a partir do século XX e início do século XXI, e desenvolvida em contextos escolares de imigrantes e indígenas que viviam na Austrália, tem consolidado resultados importantes em termos de leitura e aprendizagem em todos os níveis de ensino. Esse projeto, posteriormente, tornou-se um programa profissional e vem se configurando como uma metodologia inovadora de ensino de linguagem. Como metodologia, ela inclui uma proposta para minimizar o baixo rendimento escolar de alunos, por meio de um trabalho aprofundado com a leitura e escrita desde o Ensino Fundamental até o Ensino Superior.

No Brasil, essa perspectiva vem sendo desenvolvida no ensino de língua materna e estrangeira por diversos pesquisadores. No ensino de língua materna, Fuzer et al. (2015) reportam, por exemplo, em relatos de experiências de ensino de leitura e produção de narrativas em contos para a Educação Básica, ações realizadas por meio do projeto de extensão Ateliê de Textos, ${ }^{3}$

2 O termo "Escola de Sydney" surgiu em 1994, em referência ao trabalho com a linguagem e educação realizado no Departamento de Linguística da Universidade de Sydney.

3 O projeto iniciou as atividades em 2011 e, atualmente, é um consolidado como um Programa de Extensão da UFSM (GAP/ CAL 055400), coordenado pela Professora Dra. Cristiane Fuzer. Experiências realizadas no âmbito do Ateliê de Textos e outras informações podem ser encontradas em https://www.ufsm.br/projetos/extensao/ateliedetextos/ ou em artigos publicados: 1. FUZER, C. Ateliê de textos: (re)invenção e (re)escrita de histórias no ensino básico. Revista da Anpoll, [s. 1.], v. 1, n. 37, p. 56-79, 2014. https://doi.org/10.18309/anp.v1i37.772 , 2. FUZER, C. (org.). Ateliê de textos - para ler e reinventar estórias: do contexto ao texto e vice-versa. Santa Maria: UFSM, 2017. https://repositorio.ufsm.br/handle/1/11535 e 3. FUZER, C. et al. 
envolvendo o CEA. Os resultados alcançados indicaram que os princípios e o método de ensino adotado proporcionaram aos alunos o exercício da colaboração e união entre a turma, a partir da negociação de ideias. Além disso, os alunos envolvidos na ação de extensão relatada pelos pesquisadores tiveram oportunidade de pensar a noção de autoria ao final da produção e de colocar em prática os estudos anteriores sobre o propósito e a organização de textos que instanciam o gênero narrativa.

Até o momento, porém, não encontramos relatos de estudos e experiências em consonância com essa perspectiva na área de PLE no meio acadêmico. Por entendermos que esse modelo teórico e metodológico dialoga com documentos oficiais relacionados ao ensino de linguagem e de português, bem como com a visão de ensino do PLE-IsF, na sequência, discorremos sobre a Pedagogia de Gênero.

\subsection{Pedagogia de Gênero da Escola de Sidney}

Por mais de 30 anos, na Austrália, a partir da teoria sociológica de Bernstein (1990), que concebe a educação como um recurso pedagógico, da visão de linguagem como construto social, sustentada pela Linguística Sistêmico-Funcional de Halliday (1978), e de uma ação de pesquisa sobre letramento, Martin e Rose (2008) construíram a Pedagogia de Gênero. Nessa abordagem, os autores definem gênero de textos como uma configuração de significados, que se concretizam por meio da linguagem, atendendo os mais diversos níveis de comunicação. Assim, os gêneros, de acordo com os propósitos

Ateliê de textos: proposta metodológica para o processo de leitura e produção textual. In: CONGRESSO BRASILEIRO DE EXTENSÃo UNIVERSITÁRIA, 7, Ouro Preto MG, set. 2016. Anais. Ouro Preto, MG: UFOP, 2016. 15 p. https://www.cbeu. ufop.br/anais_files/50ab61ee4d5cd07d42f264ceca746b64.pdf. 
sociais, são agrupados em famílias (estórias; histórias; relatórios; explicações; argumentos; reações a textos e procedimentos) e segmentados em etapas específicas de cada grupo.

A construção dessa abordagem de ensino teve a sua origem nos anos 80 com o projeto conhecido como Writing Project and Language as Social Power. Na oportunidade, o alvo das pesquisas estava no letramento escolar e no estudo de textos, em termos de fases e etapas definidas consoante o propósito social, que circulavam no ensino primário. Na década de 90 , outro projeto foi desenvolvido, Write it Right, com a finalidade de investigar e descrever os gêneros de textos que os alunos deveriam aprender a ler e escrever nas escolas secundárias. Por volta de 2000, os pesquisadores passaram a desenvolver uma metodologia, a partir do projeto identificado como Reading to Learn, que, além de envolver escolas primárias e secundárias, incluiu também o desenvolvimento de uma metodologia que integra o ensino de leitura e escrita na Educação Superior (ROSE; MARTIN, 2012).

Essa visão de ensino tem emergido como uma alternativa poderosa que ultrapassa o ensino da gramática tradicional e procura proporcionar aos alunos conhecimentos explícitos sobre a língua prevista no currículo escolar. Com base na proposta de ensino de Rothery (1994), conhecida como Ciclo de Ensino e Aprendizagem, cujo objetivo é propor o ensino de modo aplicado, Martin e Rose (2005) ampliam os estudos realizados e apresentam o CEA da Pedagogia de Gênero constituído de três fases, conforme a Figura 1. 


\section{Figura 1 - Clico de Ensino e Aprendizagem}

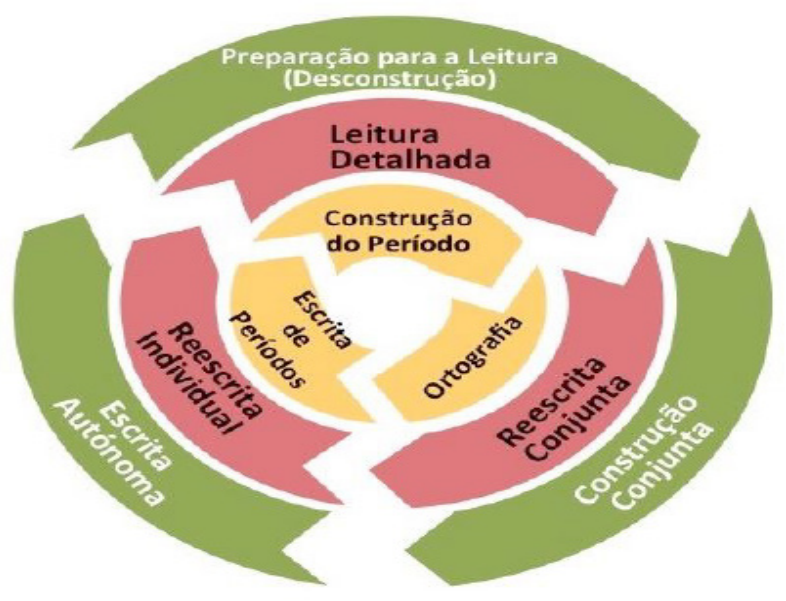

Fonte: Martin e Rose (2005). Adaptação de Gouveia (2014).

Ao discorrer sobre o Ciclo, Muniz da Silva afirma que o

círculo externo - o nível 1 do ciclo de aprendizagem inclui estratégias para que os alunos leiam e analisem o contexto e a estrutura do texto, dividindo-o em suas partes constitutivas e relacionando-as ao propósito social do texto. O foco neste nível é particularmente a estrutura de todo o texto. O círculo intermediário - nível 2 do ciclo - visa à leitura detalhada em que a linguagem é analisada conforme os padrões de significado na oração e entre orações. Por exemplo, pequenas passagens de textos são selecionadas para leitura detalhada, em seguida os alunos são convidados a reescrever usando padrões de linguagem semelhantes a fim de sistematizar conhecimentos sobre a gramática e o discurso. O círculo interno - nível 3 do ciclo - desenvolve atividades relativas a vocabulário e ortografia [...] (MUNIZ DA SILVA, 2015, p. 24-26).

Assim, o círculo externo, envolvendo o nível 1, inclui o estágio de desconstrução e prevê a realização de atividades que 
consideram o conhecimento dos alunos sobre o contexto de cultura, partindo do conhecimento que eles têm sobre o gênero, sua estrutura, seu propósito, quem o utiliza e por qual motivo, e o contexto de situação, considerando os aspectos do registro, as etapas do texto, as características da linguagem para explorar o conteúdo do texto e as relações entre quem o produz e quem o lerá.

No estágio de construção conjunta, tida como o aquecimento para a construção individual, o professor tem o papel de propor atividades que engajem os alunos na elaboração conjunta de um texto. Nesse caso, o professor escreve, no quadro ou em um programa de computador, o texto elaborado pela turma e ajuda na organização das ideias sugeridas. Nesse estágio, o professor incentiva a fazer anotações de informações importantes sobre o gênero, que os auxiliarão no próximo estágio.

E, por fim, o estágio de construção individual envolve a produção de um novo texto do mesmo gênero por parte de cada um dos alunos. Nesse estágio, o professor esclarece dúvidas da turma e torna o trabalho mais direcionado às necessidades de cada aluno. Assim, de um lado, o docente analisa cada texto e apresenta orientações para que cada aluno reflita sobre o processo de escrita; de outro, o aluno assume a função de autor e toma como base as informações apresentadas em aula e articula os conhecimentos construídos sobre o gênero em estudo no processo de escrita e reescrita.

De modo unânime, os pesquisadores que dedicam seu tempo ao estudo do CEA reportam que os alunos, ao se envolverem e se familiarizarem com o gênero estudado, percebem sua aprendizagem mais proveitosa e eficiente. Os resultados alcançados em práticas de leitura e escrita em diferentes contextos 
escolares levam a acreditar que, quando os princípios do CEA são utilizados harmoniosamente, ocorre a compreensão dos gêneros estudados, proporcionando um ensino sólido de leitura e de produção textual e contribuindo para a formação de alunos autônomos que, ao longo da vida, têm mais probabilidade de se tornarem aptos a continuar aprendendo e atuando na sociedade letrada como cidadãos participativos.

Na sequência, descrevemos o percurso mobilizado para a aplicação dos princípios apresentados no contexto de PLE-IsF da UFSM.

\section{Metodologia}

Para alcançarmos o objetivo deste estudo, mencionado na introdução, realizamos uma pesquisa sobre o contexto de ensino de PLE na UFSM e adotamos o método qualiquantitativo, de cunho interpretativista, na realização e na análise dos dados apresentados neste artigo. Esse método tem o objetivo de "compreender, descrever e, algumas vezes, explicar fenômenos sociais, a partir de seu interior, de diferentes formas" (FLICK, 2009 , p. 8).

O presente artigo, assim, é compreendido por duas fases: a primeira se configura por um levantamento do perfil e das demandas de aprendizagem dos discentes estrangeiros matriculados em cursos de graduação e de pós-graduação no campus sede da UFSM, nosso universo de análise; a segunda, pelo planejamento e pela oferta a esses estudantes de cursos de PLE no âmbito do IsF, alinhados aos princípios teóricos e metodológicos apresentados. 


\subsection{Fase 1}

Nesta fase, demos dois passos: i) o mapeamento de discentes estrangeiros matriculados em cursos de graduação e de pós-graduação no campus sede da UFSM e ii) o levantamento de suas demandas em relação à língua portuguesa. Para que fosse possível mapear onde estava nosso público-alvo, em consonância ao passo 1, entramos em contato, via e-mail, com cada uma das coordenações de curso, tendo em vista que tal informação não estava disponível na Secretaria de Assuntos Internacionais da UFSM, nem no Departamento de Registro Acadêmico dessa instituição.

Na UFSM, os cursos de graduação e de pós-graduação são vinculados a Unidades de Ensino de acordo com sua área de concentração. São as Unidades de Ensino do campus em tela: Centro de Artes e Letras (CAL), Centro de Ciências Naturais e Exatas (CCNE), Centro de Ciências da Saúde (CCS), Centro de Ciências Sociais e Humanas (CCSH), Centro de Ciências Rurais (CCR), Centro de Educação (CE), Centro de Educação Física e Desporto (CEFD), Centro de Tecnologia (CT), Colégio Técnico e Industrial de Santa Maria (CTISM) e Colégio Politécnico (POLI).

Objetivamos, com esse passo, ter acesso não só ao número de estudantes estrangeiros vinculados a cada Unidade de Ensino, mas também ao contato desses estudantes, que é fundamental ao passo 2 desta fase da pesquisa. $\mathrm{O}$ resultado do levantamento encontra-se na seção 4, a qual tem por objetivo justamente expor dados tanto de cunho qualitativo quanto quantitativo.

Com o mapeamento dos cursos em que os estrangeiros estavam vinculados e com seu contato de e-mail, partimos ao 
passo 2: realizar o levantamento das demandas que esse público tem em relação à aprendizagem da Língua Portuguesa. Para isso, criamos, por meio do Google Forms, um formulário de identificação do perfil dos interessados em cursos de PLE a serem ofertados pelo IsF na UFSM.

O questionário criado tinha por objetivo conhecer o público estrangeiro da instituição, bem como saber se estavam e, se sim, de que forma os estudantes estavam se adaptando ao ensino remoto (tendo em vista que a pesquisa ocorreu durante o distanciamento social imposto pela pandemia da Covid-19) e suas demandas de aprendizagem da Língua Portuguesa. Ao todo, o questionário, enviado por e-mail aos estudantes mapeados no passo 1 desta fase, era composto por sete questões, dentre elas a elucidada na Figura 2.

4 Neste artigo, considerando o espaço disponível e em consonância ao nosso objetivo, optamos por realizar um recorte e apresentar apenas a questão referida. 
Figura 2 - Amostragem de questão do formulário de levantamento das demandas de discentes estrangeiros na UFSM

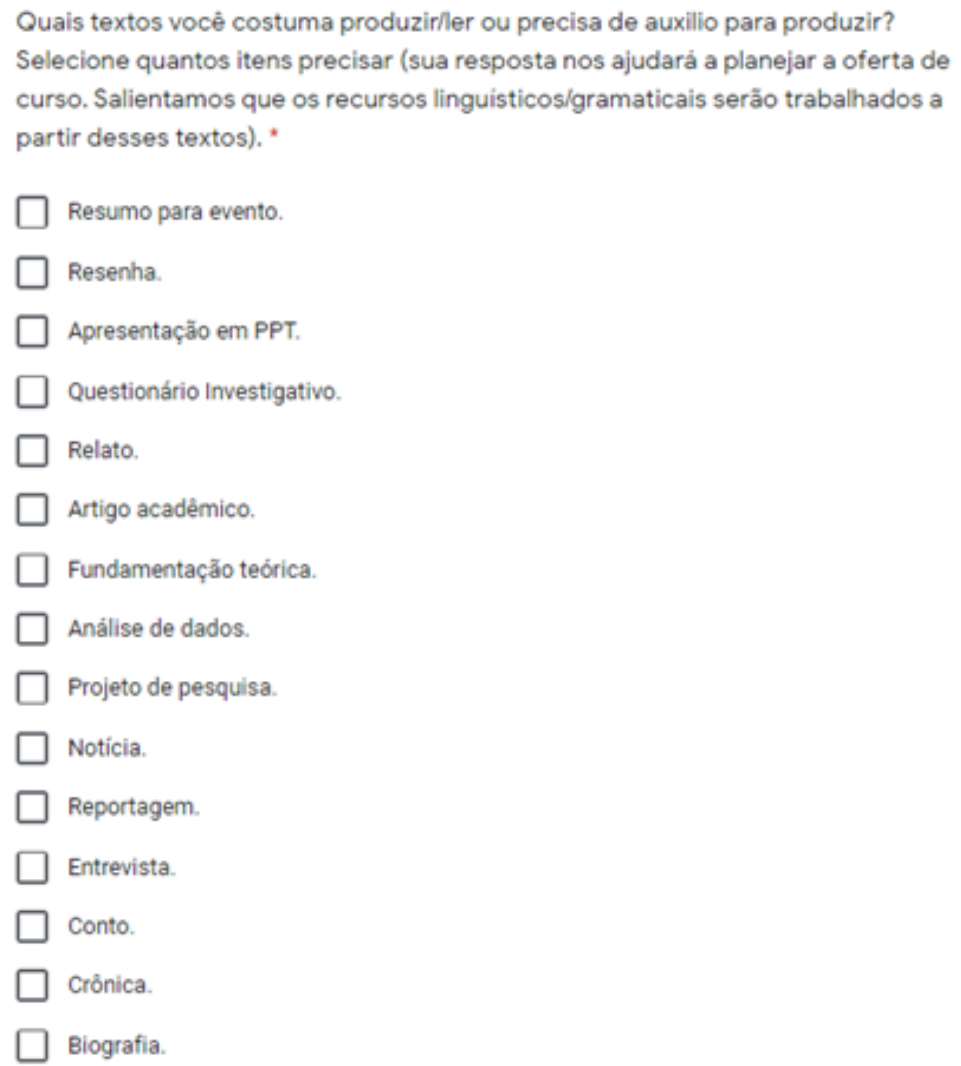

Fonte: Elaborado pelos autores.

A questão tinha como objetivo investigar quais gêneros de texto eram consumidos e produzidos pelos estrangeiros vinculados à UFSM, campus Santa Maria. O termo "gênero" não foi empregado para que o texto fosse de mais fácil entendimento. As respostas dadas a essa questão foram essenciais para o desenvolvimento da fase 2 , apresentada na sequência. 


\subsection{Fase 2}

Diante das respostas fornecidas pelos estudantes estrangeiros matriculados em cursos de graduação e de pós-graduação no campus sede da UFSM, trabalhamos na tentativa de aproximar as demandas apresentadas à proposta teórica e metodológica que embasa o ensino de PLE no âmbito do IsF na UFSM - a pedagogia com base em gêneros de textos. De acordo com essa abordagem, é preciso considerar o contexto de aprendizagem e trabalhar os aspectos linguísticos por meio de textos autênticos.

O planejamento dos cursos a serem ofertados precisou, assim, considerar que as aulas seriam ministradas de forma remota, modalidade de ensino que possui especificidades diferentes do modelo a distância, ${ }^{5}$ por exemplo, no qual já se tem registros de ofertas de cursos de PLE. Nesse sentido, a primeira decisão metodológica nossa, no que tange à dinamização dos cursos, foi pelo uso do Moodle, disponibilizado pelo IsF da UFSM gratuitamente, como Ambiente Virtual de Ensino e Aprendizagem (Avea); além disso, para encontros síncronos, optamos pelo uso da ferramenta Google Meet.

$\mathrm{Na}$ sequência, foi preciso eleger quais seriam os gêneros de texto a serem estudados em cada um dos cursos ofertados. Consideramos, para tal escolha, os gêneros instanciados em textos aos quais os discentes estrangeiros têm acesso em seu cotidiano, com base nas respostas à questão elucidada na Figura 2. O formato das aulas, a proposta de cronograma e o gênero de texto base de um dos cursos ofertados pelo PLE-IsF na UFSM, oriundos desse levantamento, são apresentados e discutidos na seção seguinte.

\footnotetext{
5 Mais informações sobre tais distinções podem ser encontradas em: https://cietenped.ufscar.br/submissao/index.php/2020/ article/view/1705.
} 


\section{Análises e discussão}

Esta seção apresenta, em um primeiro momento, os dados obtidos no mapeamento das Unidades de Ensino a que estão vinculados os cursos de graduação e pós-graduação que abrigam os discentes estrangeiros matriculados na UFSM, campus Santa Maria, bem como o perfil desse alunado. Na sequência, apresentamos a proposta de curso originária da demanda descrita, atrelada aos princípios da Escola de Sidney.

\subsection{Estrangeiros matriculados na UFSM}

A partir do contato estabelecido com as coordenações dos cursos de graduação e pós-graduação, foi possível mapearmos 68 estrangeiros. O nível de ensino em que estão matriculados esses estrangeiros pode ser conferido no Quadro 1.

\section{Quadro 1 - Nível de ensino dos estudantes estrangeiros da UFSM}

\begin{tabular}{|l|l|}
\hline Número de estrangeiros em cursos de graduação & 28 \\
\hline Número de estrangeiros em cursos de pós-graduação & 40 \\
\hline Total de estrangeiros mapeados & 68 \\
\hline
\end{tabular}

Fonte: Elaborado pelos autores.

Os números apresentados no levantamento expressam a ocorrência de um maior índice $(58,8 \%)$ de alunos estrangeiros matriculados em programas de pós-graduação (PPGs) em relação ao público matriculado na graduação $(41,7 \%)$. Podemos atribuir a diferença à política de internacionalização da universidade, que prevê maior fomento nos níveis de mestrado e doutorado. 
Em relação às Unidades de Ensino em que se encontram os cursos em que esses discentes estavam matriculados, podemos perceber, no Quadro 2, uma predominância do Centro de Tecnologia, com 20 estudantes.

\section{Quadro 2 - Unidades de Ensino}

\begin{tabular}{|l|r|}
\hline Número de estrangeiros vinculados ao CAL & 5 \\
\hline Número de estrangeiros vinculados ao CCNE & 17 \\
\hline Número de estrangeiros vinculados ao CCS & 8 \\
\hline Número de estrangeiros vinculados ao CCSH & 7 \\
\hline Número de estrangeiros vinculados ao CCR & 11 \\
\hline Número de estrangeiros vinculados ao CT & 20 \\
\hline Número de estrangeiros vinculados ao CE & 0 \\
\hline Número de estrangeiros vinculados ao CEFD & 0 \\
\hline Número de estrangeiros vinculados ao CTISM & 0 \\
\hline Número de estrangeiros vinculados ao POLI & 0 \\
\hline
\end{tabular}

Fonte: Elaborado pelos autores.

No CT, estão alocados os cursos de Arquitetura e Urbanismo, Ciências da Computação, Sistemas de Informação e as mais diversas Engenharias e seus respectivos PPGs. Saber a área de concentração dos estudos dos estrangeiros qualifica nossas inferências sobre eles, o que, para Reddy (2000), pode direcionar o professor a utilizar estratégias pedagógicas mais eficazes para seu público. Outra Unidade de Ensino que se destaca no Quadro 2 é o CCNE, nela estão os cursos de Ciências Biológicas, Estatística, Física, Geografia, Matemática, Meteorologia, Processos Químicos e Química, bem como seus PPGs. Diante da diversidade formativa expressa entre as duas Unidades de Ensino com mais estudantes estrangeiros vinculados, percebemos que apenas esse levantamento de inferências poderia não atender 
nossas demandas sobre o contexto de situação em que a prática docente foi desenvolvida, informação fundamental para o desenvolvimento do trabalho com o CEA. Assim, emergiu a necessidade de contatar os discentes, conforme apresentado na metodologia e discutido na sequência.

Em consonância ao passo 2 da fase relatada da pesquisa, contatamos, via e-mail, os discentes estrangeiros mapeados e enviamos a eles o questionário elaborado, conforme mencionado na seção 3. Ao todo, obtivemos um total de 27 respondentes. Podemos considerar, como argumento ao fato de nem todos terem respondido ao questionário, os reflexos da pandemia.

Quando questionados sobre o formato que os estudantes preferiam para a realização das aulas, a maioria, conforme pode ser visto na Figura 3, sinalizou interesse em distribuir a carga horária dos cursos de PLE entre encontros síncronos e atividades assíncronas.

Figura 3 - Formato das aulas

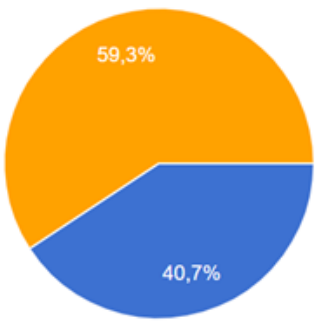

Fonte: Elaborado pelos autores

Com 59,3\%, a opção de alternar entre os tipos de atividades a serem desenvolvidas se fez privilegiada quando em comparação com a opção da realização de toda a carga horária de forma 
síncrona, sinalizada por $40,7 \%$ dos respondentes. Acreditamos que esse formato tenha sido privilegiado devido à forma como as aulas de maior parte dos cursos de graduação e de pósgraduação da UFSM estarem ocorrendo. Desse modo, cabe aos alunos, além de participar das discussões realizadas por meio de videoconferências, realizar exercícios, leituras e discussões assíncronas via Moodle, Avea do IsF na UFSM.

Em se tratando dos gêneros de texto que os estrangeiros mobilizam em seu cotidiano, as respostas foram diversas. Receberam, contudo, destaque os gêneros específicos do ambiente universitário, dentre eles, a resenha, indicada como essencial para $62,9 \%$ dos discentes.

Acreditamos que tal gênero de texto tenha sido amplamente sinalizado tendo em vista que seu propósito sociocomunicativo, avaliar um objeto cultural, se faz presente na rotina daqueles que vivenciam a prática acadêmica. Diante disso, percebemos que esse deveria ser um dos gêneros trabalhados ao longo de um dos cursos a ser planejado e desenvolvido no âmbito do PLE-IsF na UFSM. Na seção seguinte, apresentamos os cursos propostos ao encontro das demandas levantadas e exemplificamos, a partir de um deles, como a metodologia descrita pelos pesquisadores da Escola de Sidney foi desenvolvida nesse outro contexto.

\subsection{Planejamento de cursos}

Diante da demanda exposta na seção anterior, foram planejados e ofertados cinco cursos de PLE no âmbito do IsF na UFSM no ano de 2020. Os cursos buscaram aliar o aprendizado da língua - de questões léxico-gramaticais e semântico-discursivas - ao aprendizado pela língua - de questões culturais do Brasil, por exemplo. O Quadro 3 evidencia os cursos ofertados e suas respectivas cargas-horárias. 
Quadro 3 - Cursos ofertados

\begin{tabular}{|l|c|}
\hline \multicolumn{1}{|c|}{ Curso } & Carga-horária \\
\hline Leitura e produção textual: princípios básicos & $32 \mathrm{~h}$ \\
\hline Cine debate & $16 \mathrm{~h}$ \\
\hline Familiarização com o Exame Celpe-Bras & $16 \mathrm{~h}$ \\
\hline Exame Celpe-Bras: parte oral & $16 \mathrm{~h}$ \\
\hline Diálogos interculturais & $16 \mathrm{~h}$ \\
\hline
\end{tabular}

Fonte: Elaborado pelos autores.

A fim de exemplificar o preceito de preservar o ensino da língua atrelado ao ensino pela língua, a Figura 4 retrata a ementa de um dos cursos ofertados, no qual enfocamos o estudo de resenhas, maior demanda dos estrangeiros que responderam ao questionário de sondagem, Cine debate.

\section{Figura 4 - Ementa do curso Cine debate}

Rede Idiomas sem Fronteiras

Universidade Federal de Santa Maria

Português Lingua Estrangeira/Adicional

Ementa de curso

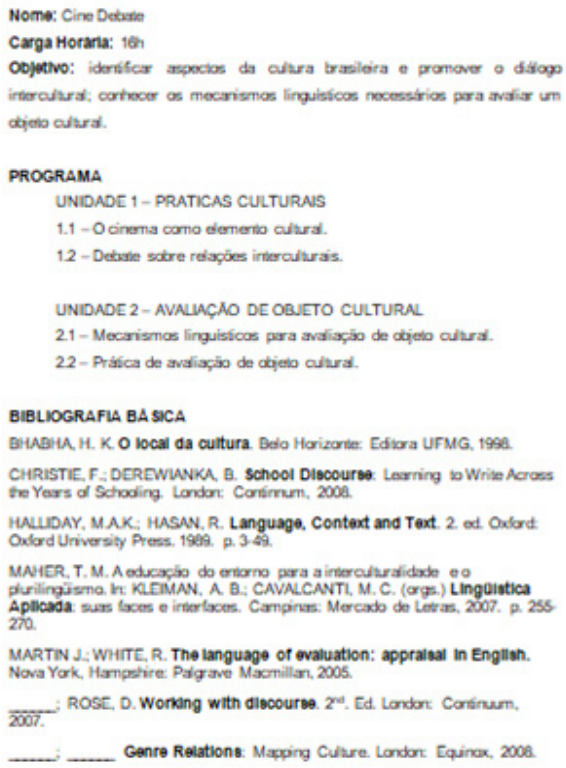

Fonte: Elaborado pelos autores. 
Durante o curso, enquanto eram apresentadas algumas noções sobre o funcionamento característico da linguagem das resenhas, os alunos também compreendiam algumas representações, crenças, visões de mundo e alguns hábitos dos brasileiros. Assim, os acadêmicos estrangeiros puderam construir e internalizar aspectos linguísticos e culturais próprios da linguagem em determinados contextos, tal como preconiza a perspectiva da Escola de Sidney.

O curso, considerando as respostas dos discentes ao formulário de sondagem, foi desenvolvido a partir de encontros síncronos e de proposição de atividades assíncronas. A Figura 5 elucida a distribuição semanal do tempo empregado pelo professor para a realização da oferta.

\section{Figura 5 - Distribuição das atividades semanais do curso}

\section{Cine Debate}

\begin{tabular}{|c|c|c|c|c|c|}
\hline & Segunda-feira & Terça-feira & Quarta-feira & Quinta-feira & Sexta-feira \\
\hline $\begin{array}{c}\text { Das } 9 \mathrm{~h} 30 \mathrm{~min} \\
\text { às } 11 \mathrm{~h}\end{array}$ & & & & & $\begin{array}{c}\text { Plantão para } \\
\text { auxilio nas } \\
\text { atividades } \\
\text { assincronas - Cine } \\
\text { debate }\end{array}$ \\
\hline Das $11 \mathrm{~h}$ às $12 \mathrm{~h}$ & & $\begin{array}{c}\text { Monitoria - Cine } \\
\text { debate }\end{array}$ & & & \\
\hline $\begin{array}{c}\text { Das } 16 \mathrm{~h} 30 \mathrm{~min} \\
\text { às } 18 \mathrm{~h}\end{array}$ & $\begin{array}{l}\text { Aula sincrona - } \\
\text { Cine debate }\end{array}$ & & & & \\
\hline
\end{tabular}

Fonte: Elaborado pelos autores.

Os encontros semanais ocorriam às segundas-feiras, das $16 \mathrm{~h} 30 \mathrm{~min}$ às $18 \mathrm{~h}$, totalizando $1 \mathrm{~h} 30 \mathrm{~min}$ de aula síncrona. Além disso, para completar a carga horária semanal do curso (4h), o tempo restante foi previsto para a realização de atividades propostas pelo professor, o qual ficava disponível, às sextasfeiras, das $9 \mathrm{~h} 30 \mathrm{~min}$ às $12 \mathrm{~h}$, para auxiliar os discentes no cumprimento de tais atividades. Por fim, foi incluída $1 \mathrm{~h}$ semanal para a realização de monitorias, mediante agendamento. 
Para que fosse possível atingir, com qualidade, o objetivo do curso, a partir da abordagem da Pedagogia de Gêneros, foi proposto o cronograma de aulas que pode ser visto na Figura 6 . Os alunos, no início do curso, tiveram acesso a esse documento, bem como a informações da sistemática das aulas e das avaliações.

Figura 6 - Cronograma do curso Cine Debate

\begin{tabular}{|c|c|c|}
\hline & Aula sincrona & Atividade assincrona \\
\hline 1 & $\begin{array}{l}\text { Discussão oral: } 0 \text { cinema como } \\
\text { elemento cultural. }\end{array}$ & Assistir ao filme 1. \\
\hline 2 & $\begin{array}{l}\text { Desconstrução do gênero: } \\
\text { mecanismos linguísticos para } \\
\text { avaliação de objeto cultural - } \\
\text { exposição da estrutura esquemática } \\
\text { e dos elementos linguisticos } \\
\text { tipicamente instanciados no gênero } \\
\text { de texto resenha. }\end{array}$ & Assistir ao filme 2 . \\
\hline 3 & $\begin{array}{l}\text { Debate sobre relações interculturais } \\
\text { a partir dos elementos observados } \\
\text { nos filmes } 1 \text { e } 2 \text {. } \\
\text { Construção conjunta da resenha do } \\
\text { Filme } 1\end{array}$ & $\begin{array}{l}\text { Produção da primeira versão de } \\
\text { uma resenha sobre o Filme } 2 \text {. }\end{array}$ \\
\hline 4 & $\begin{array}{l}\text { Orientação individual, por } \\
\text { agendamento, para a reescrita da } \\
\text { resenha. }\end{array}$ & $\begin{array}{l}\text { Produção da segunda versão de } \\
\text { uma resenha sobre o Filme } 2 \text {. }\end{array}$ \\
\hline
\end{tabular}

Fonte: Elaborado pelos autores.

Podemos perceber, na Figura 6, que o planejamento das aulas foi ao encontro da corrente teórica e metodológica apresentada na seção 2. Os três estágios do CEA - desconstrução do gênero, construção conjunta e construção individual - são desenvolvidos ao longo das quatro semanas de curso.

$\mathrm{Na}$ primeira semana, a proposta de aula síncrona foi direcionada à aproximação dos alunos às questões do campo do curso - o cinema. A tarefa assíncrona - assistir a um filme do cinema nacional - serviu de base para a realização da aula 3.

Na segunda semana, o gênero de texto alvo desse curso 
— a resenha - foi enfocado, realizando-se, assim, o momento da desconstrução. $\mathrm{Na}$ atividade síncrona, o professor partiu dos conhecimentos dos alunos para sistematizar as noções de propósitos sociocomunicativos e de estrutura esquemática da resenha e os recursos linguísticos que a realizam. ${ }^{6}$ Além disso, foram propostos e realizados, em conjunto, exercícios de análise linguística. Como atividade assíncrona, os alunos assistiram a mais um filme, o qual também foi objeto de discussão da aula 3.

$\mathrm{Na}$ terceira semana, durante o encontro síncrono, além de debaterem aspectos culturais presentes nos filmes assistidos, os estudantes, dando sequência ao que postula o CEA, construíram conjuntamente, com a mediação do professor, uma resenha do filme assistido na semana 1. Como atividade assíncrona, dando início ao outro momento do CEA, na referida semana, os alunos produziram, individualmente, a primeira versão de suas resenhas sobre do filme 2 .

$\mathrm{Na}$ quarta semana, foram realizados encontros individuais entre professor e alunos para orientações sobre aspectos que estavam adequados nos textos e os que deveriam ser reescritos, bem como sobre a forma como o aluno deveria proceder à reescrita. Como atividade assíncrona, os alunos reescreveram suas resenhas.

Ao fim da dinamização do CEA, percebemos que a noção de gênero, texto e contexto, além de aspectos relacionados à estrutura e ao funcionamento da língua portuguesa em resenhas e a valores da cultura brasileira, foi internalizada pelos alunos. Isso ficou evidente nos textos produzidos pela turma, os quais serviram como instrumento de avaliação do processo de ensino

6 Barros e Fuzer (2020) realizaram um estudo sobre resenhas em livro didático de língua portuguesa a partir do mesmo viés teórico deste trabalho. 
e aprendizagem, reportado no presente artigo, e da eficácia dos postulados de Martin e Rose (2008) e de Rose e Martin (2012) no contexto de PLE.

Os textos finais produzidos pelos estrangeiros estão disponíveis no formato e-book. ${ }^{7}$ A socialização dos produtos obtidos ao longo do processo é uma prática consoante aos estudos que embasam o trabalho de PLE no âmbito do IsF na UFSM. Na seção seguinte, nossas considerações finais acerca das discussões até aqui apresentadas.

\section{Considerações finais}

Neste artigo, apresentamos princípios do CEA norteadores no desenvolvimento de cursos, bem como resultados de uma experiência de ensino de PLE no âmbito do IsF na UFSM. De acordo com o que reportaram pesquisadores, a realização de atividades de desconstrução, construção conjunta e individual de textos requer a participação ativa e colaborativa dos acadêmicos e proporciona a familiarização com o gênero estudado, a aprendizagem de aspectos linguísticos, discursivos e culturais, conforme discutido na seção 4 deste trabalho.

Os resultados discutidos, a partir de práticas de leitura e escrita, levam-nos a acrescentar que a dinamização do CEA, em contexto de PLE, possibilita a plena compreensão das características dos gêneros estudados e proporciona o uso consciente e autônomo da linguagem. A recorrência de práticas de ensino calcadas na abordagem adotada sugere uma probabilidade de que os estrangeiros se tornem proficientes na língua e aptos a continuar aprendendo e atuando na sociedade letrada como cidadãos participativos.

7 E-book disponível em: https://issuu.com/guilherme_barbat/docs/um_olhar_estrangeiro_para_classicos_do_cinema_naci. 
Referências

ALLWRIGHT, D. The death of the method. Sgav Conference. Ottawa: Carleton University, 1991.

ALMEIDA FILHO, J. C. P. de. Fundamentos de abordagem e formação no ensino de Português Língua Estrangeira e outras línguas. Campinas: Pontes, 2011.

ALMEIDA FILHO, J. C. P. de. Linguística aplicada, ensino de línguas e comunicação. Campinas: Pontes, 2005.

ALMEIDA FILHO, J. C. P. de. Projetos iniciais em português para falantes de outras línguas. Campinas: Pontes, 2007.

ANDIFES. Associação Nacional dos Dirigentes de Instituições de Ensino Superior. Programa de expansão, excelência e internacionalização das universidades federais. Brasília, 2012.

ASSIS-PETERSON, A. M. Alguns apontamentos em torno da formação de professores de língua estrangeira. Contexturas, $[s$. l.], n. 4, p. 43-50, 1999.

BARROS, G. B.; FUZER, C. Análise sistêmico-funcional de resenhas em livro didático de Língua Portuguesa. MacabéaRevista Eletrônica do Netlli, [s. l.], v. 9, n. 4, p. 398-415, 2020. BERNSTEIN, B. The Structuring of Pedagogic Discourse. Londres: Routledge, 1990.

BRASIL. Parâmetros Curriculares Nacionais: terceiro e quarto ciclos: Língua Portuguesa. Brasília: MECSEF, 1998.

BRASIL. Parâmetros Curriculares Nacionais: terceiro e quarto ciclos: Matemática. Brasília: MECSEF, 1998.

DINIZ, L. R. A. Mercado de línguas: a instrumentalização brasileira do português como língua estrangeira. 2008. $208 \mathrm{f}$. Dissertação (Mestrado em Linguística) - Unicamp, Campinas, 
2008. Disponível em: <http://repositorio.unicamp.br/bitstream/ REPOSIP/271065/1/Diniz_LeandroRodriguesAlves_M.pdf > . Acesso em: 31 mar. 2021.

DINIZ, L. R. A. Política linguística do Estado brasileiro na contemporaneidade: a institucionalização de mecanismos de promoção da língua nacional no exterior. 2012. 396 f. Tese (Doutorado em Linguística) - Unicamp, Campinas, 2012. Disponível em: <http://repositorio.unicamp.br/bitstream/ REPOSIP/271080/1/Diniz_LeandroRodriguesAlves_D.pdf $>$. Acesso em: 31 mar. 2021.

FLICK, U. Qualidade na pesquisa qualitativa. Porto Alegre: Grupo A, 2009. (Coleção Pesquisa Qualitativa).

FURTOSO, V. B. O ensino de língua estrangeira: o foco no professor. UNOPAR Cient., Ciênc. Hum. Educ., Londrina, v. 2, n. 1, p. 67-82, jun. 2001.

FUZER, C. et al. Experiências de desconstrução de gênero e escrita conjunta no projeto Ateliê de Textos. In: SIEDUCA, 20., 2015.

GOUVEIA, C. A. M. A compreensão leitora como base instrumental do ensino da produção escrita. In: SILVA DOS SANTOS, W. R. J. S.; MELO, M. A. Pesquisas em língua(gem) e demandas do ensino básico. São Paulo: Pontes, 2014. p. 203231.

HALLIDAY, M. A. K. Language as social semiotic. London: Edward Arnold, 1978.

KNIGHT, J. The internationalization of higher education in the 21st century: new realities and complexities. In: KNIGHT, J. Higher education in Turmoil: the changing world of internationalization. Brill, 2008.

KUMARAVADIVELU, B. The postmethod condition: (e) merging strategies for second/foreign language teaching. Tesol Quarterly, [s. l.], v. 26, n. 1, p. 27-48, 1994. 
LEFFA, V. O ensino das línguas estrangeiras no contexto nacional. Contexturas, APLIESP, [s. l.], n. 4, p. 13-24, 1999.

MARTIN, J. R.; ROSE, D. Designing literacy pedagogy: scaffolding democracy in the classroom. In: WEBSTER, J.; MATTHIESSEN, C.; HASAN, R. Continuing discourse on language. London: Continuum, 2005. p. 251-280.

MARTIN, J. R.; ROSE, D. Genre relations: mapping culture. Equinox Publishing Ltd., 2008.

MOITA LOPES, L. P. da (org.). O português no século XXI: cenário geopolítico e sociolinguístico. São Paulo: Parábola, 2013.

MUNIZ DA SILVA, E. C. Ciclo de aprendizagem baseado em gêneros. Linguagem - Estudos e Pesquisas, Catalão-GO, [s. l.], v. 19, n. 2, p. 19-37, jul./dez. 2015.

NÓBREGA, M. H. da. Ensino de Português para nativos e estrangeiros: na prática, a teoria é outra. Linha D’Água, [s. l.], p. 25-40, 2010.

OLIVEIRA, G. M. Um Atlântico ampliado: o português nas políticas linguísticas do século XXI. In: MOITA LOPES, L. P. da (org.). O Português do século XXI: cenário geopolítico e sociolinguístico. São Paulo: Parábola, 2013. p. 53-73.

PRABHU, N. S. There is no best method-why? Tesol Quarterly, [s. l.], v. 24, n. 2, p. 161-176, 1990.

REDDY, M. J. A metáfora do conduto: um caso de conflito de enquadramento na nossa linguagem sobre a linguagem. Cadernos de tradução, [s. l.], v. 9, p. 1-72, 2000.

RICHARDS, J. C.; NUNAN, D. (ed.). Second language teacher education. New York: Cambridge University Press, 1990.

ROCHA, N. A. O ensino de Português língua estrangeira no Brasil: ontem e hoje. Linguagens - Revista de Letras, Artes e Comunicação, Blumenau, v. 13, n. 1, p. 101-114, jan./abr. 2019. 
ROSE, D.; MARTIN, J. R. Learning to write, reading to learn: genre, knowledge and pedagogy in the Sydney School. Sheffield (UK) and Bristol (USA): Equinox Publishing Ltd., 2012.

ROTHERY, J. Exploring literacy ill School English (Write if right resources for literacy and learning). Sydney: Metropolitan East Disadvantaged Schools Program, 1994.

WELP, A. K. D. S.; FONTES, A.; SARMENTO, S. O Programa Inglês sem Fronteiras na Universidade Federal do Rio Grande do Sul. Do inglês sem fronteiras ao idioma sem fronteiras: a construção de uma política linguística para a internacionalização. Belo Horizonte: Editora da UFMG, 2016.

ZOPPI FONTANA, M. (org.). O português como língua transnacional. Campinas: RG, 2009. 